\title{
Gente queer: masculinidades femeninas y el dilema de las identidades
}

\section{Álvaro Carvajal Villaplana ${ }^{1}$}

Recepción: 21 de abril de 2014 / Aprobación: 3 de junio de 2014

\section{Resumen}

Este ensayo se plantea hacer un análisis de las masculinidades femeninas, concepto que se toma de Judith (Jack) Halberstam. El análisis se hace a partir de varias películas que muestran la diversidad de las masculinidades femeninas; sin embargo, el interés de este ensayo se centra en los transgéneros y transexuales de mujer a hombre, por representar el extremo de un continuo en el que los cuerpos hembriles asumen identidades masculinas. Pero el caso de los transgéneros y transexuales, más allá de cuestiones culturales e identitarias, plantea problemas de fondo sobre la relación entre los aspectos biológicos y los culturales, de tal manera que en este ensayo se establece cómo en las personas transgénero y transexuales se interrelaciona la biología con la cultura, por lo cual se propone un modelo bidireccional y un empirismo mínimo. Este estudio se ubica en un enfoque perteneciente a la filosofía analítica.

\section{Palabras clave}

Transgénero; transexualidad; lesbianismo; masculinidad; masculinidad femenina

\section{Abstract}

This essay presents an analysis of Judith Halverstam's concept of feminine masculinities. Several movies that shown the diversity of the feminine masculinities are taken as the basis or the analysis however, the focus of the essay are the transgender and the transsexual from women to men in order to show one of the extreme parts of a continuum in which female bodies assume masculine identities. The case of this group goes beyond cultural and identity issues; it possess substantive problems about the relationship between biological and cultural aspects. Thus, this essay discusses how in the transgender and the transsexual people biology interrelates with culture thus, a bidirectional model and a minimal empiricism can be found. This study is located in an approach called analytic philosophy.

1 Costarricense. Doctor en Humanidades con énfasis en Filosofía Contemporánea, grado obtenido en la Universidad Carlos III de Madrid, España. Director del Programa de Posgrado en Filosofía, Universidad de Costa Rica. Correo electrónico: acarvajalvillaplana@hotmail.com 


\section{Key Words}

Transgender; transsexuality; lesbianism; masculinity; female masculinity

\section{Resumo}

Este ensaio apresenta uma análise da masculinidade do sexo feminino, um conceito que é tirado de Judith Halberstam. Este estudo foi feito a partir de vários filmes que mostram a diversidade da masculinidade do sexo feminino, no entanto, o objetivo deste ensaio versa sobre transgênero e transexual feminino para masculino para representar o fim de um continuum em que os corpos hembriles assumir identidades masculinas. Mas o caso de travestis e transexuais, além de questões culturais e de identidade, problemática de fundo sobre a relação entre aspectos biológicos e culturais, de modo que neste ensaio discute como transgêneros e transexuais se inter-relaciona biologia e cultura, para um modelo de duas vias e empirismo mínima surge. Este estudo situase em uma abordagem chamada filosofia analítica.

\section{Palavras-chave}

Transexuais; transexualidade; lesbianismo; a masculinidade; a masculinidade do sexo feminino

\section{Introducción}

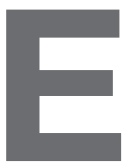

n este artículo se aborda un tema complejo sobre las maneras de ser y hacerse masculino por parte de los cuerpos y las identidades femeninas. El término masculinidad femenina se toma de la teórica queer Judith Halberstam, de un libro intitulado de la misma manera, el cual data de 1998 y su traducción castellana es de 2008.

El concepto intenta recoger o representar la realidad masculina de las mujeres queer. A veces simplemente se trata de mujeres heterosexuales que tienen apariencia masculina; en otras, de lesbianas que asumen comportamientos, actitudes y formas de vestir masculinas o de lesbianas masculinizadas que asumen roles masculinos; también, remite a personas transgénero y transexuales de mujer a hombre. A este respecto, Halberstam dice que se trata de "la fusión de una conducta masculina con un cuerpo de mujer" (2008, 7). Esta última acepción es restrictiva y encaja mejor con el término masculinidades femeninas, ya que refiere a las situaciones de los transgénero y los transexuales de mujer a hombre, las cuales son el objeto de análisis de este artículo.

En castellano, algunas de las palabras que remiten a la idea de masculinidad femenina son camionera, chicazo, marimacha, manflora, bombero y trailera, entre otras. En inglés, los términos no académicos para referirse a este grupo humano son dyke, butch, y stone butch, entre otros. 
Al igual que en el caso de personas transgénero y transexuales de hombre a mujer (mujeres trans), a los transgénero y los transexuales de mujer a hombre (hombres trans) se les identifica con el típico comportamiento que se asigna a las lesbianas, por lo que, por lo general, se tiende a generalizar que todas las mujeres lesbianas son mujeres masculinas. Esto, a la vez, genera un estereotipo que no recoge la riqueza de la realidad de las lesbianas ni la de los hombres trans. Sin embargo, lo anterior no niega que existan ciertas lesbianas que tienden a identificarse con las formas de vestir o comportarse del género opuesto.

Así, desde el punto de vista común, se considera que las lesbianas son hombrunas, lo que produce extrañeza. No obstante, a veces, ser y comportarse como hombre resulta menos visible, contrario a cuando un hombre asume el género femenino. Pero, desde el punto de vista teórico y político, el rechazo se da por otras razones, es decir, porque estos cuerpos femeninos asumen el género del patriarcado o intentan imitar la "cultura del macho", lo cual, tampoco niega los esfuerzos de algunos hombres trans por construir una identidad masculina diferenciada del estereotipo masculino considerado patriarcal. En este caso, el uso del término patriarcal puede implicar la discriminación y la exclusión de un grupo humano, en particular, por parte de ciertos enfoques feministas.

Además de esta identificación entre lesbianas y hombres trans o masculinidades femeninas, también se tiende a confundir la realidad de la homosexualidad con el de transexualidad y el transgénero. Como se analizará, estos fenómenos son diferentes, mientras que el primero marca una atracción por personas del mismo sexo; en los segundos, las personas se sienten o son del género contrario, y por lo general, estas personas no son homosexuales. Sin embargo, a veces parece que el linde entre la homosexualidad y la transexualidad no es claro y existen zonas grises, lo que complica el poder trazar fronteras precisas.

Existe una tendencia entre el movimiento gai ${ }^{2}$ y lesbiano a diferenciarse de la transexualidad y el transgénero. La identidad gai y lesbiana se comenzó a construir, entre uno de sus aspectos, distanciándose de la transexualidad. Según Gerard Coll-Planas, este distanciamiento se establece a partir de distinguir entre identidad de género y tendencia sexual, lo que lleva a la mencionada separación conceptual. Esta diferenciación ha llevado a la exclusión de los transexuales del movimiento gai y lesbiano. A este respecto, el movimiento trans se ha ubicado en una perspectiva teórica que critica la discriminación que se ejerce desde el mismo movimiento gai-lesbiano (Coll-Planas, 2010, 224). En contraste, Coll-Planas, ya no desde el sentido común, sino desde una perspectiva teórica, aboga porque tal distinción no existe, aunque no parece que esta posición pueda sostenerse.

2 En este ensayo se usa el término "gai" en lugar del inglés "gay", dado que, en castellano, existe el término "gay" que procede del latín Goucidum (gozo, alegre). En masculino es "goyo", en femenino "gaya". También puede usarse el occitano "gai", con el mismo sentido del término inglés. 
En este artículo, a partir del análisis de seis filmes se intenta hacer una representación de la diversidad de la masculinidad femenina; sin embargo, la mayoría de los filmes no logran captar en su plenitud tal concepto, salvo la película Boys Don't Cry (1993), de Kimberly Peirce, y el documental Falso orgasmo (2010), de Steve Miles. El primero define un territorio de la diversidad sexual, el segundo es un filme que se ubica en las fronteras entre la transexualidad, el transgénero y el lesbianismo. Las otras películas muestran a mujeres masculinas o masculinizadas que a veces parecen identificarse como hombres, en ocasiones como lesbianas. Por ejemplo, en Un amor diferente (2005), de Alice Wu, el personaje principal asume el apodo masculino Wil; quien presenta una mezcla entre una imagen femenina y una vestimenta masculina, pero ella no se siente hombre, sino lesbiana.

En Garzon Maudit (1995), de Joseave Belasko, el personaje transgénero, Marie-Jo, cumple con el estereotipo de la denominada camionera o trailera, la que se identifica con la lesbiana. En el filme no queda claro, en especial por la traducción al castellano, que Marie-Jo se considere un hombre, aunque se comporta como uno. A la vez, el filme marca las zonas grises, ya que Marie-Jo no renuncia a su maternidad ni al cuerpo hembril.

Más interesante es la película Two Girls in Love (1995), de María Mangenti, pues el filme muestra la realidad del transgénero, donde Randall Dean se muestra como a una persona con un cuerpo hembril que asume la masculinidad de un adolescente, aunque una de las voces secundarias se refiere a Randall como una "lesbiana que hace de hombre". Uno de los aspectos interesantes del filme es el juego de roles masculino-femenino entre Randall y Evie, o entre la tía de Randall y su pareja. Además, del modelo familiar queer, al que filme refiere, aparece como un "hogar normal de lesbianas".

En la película Tan de repente (2002), de Diego Lerma, se muestra otro tipo de masculinidades femeninas. Los personajes transgénero, Elena (Verónica) y Maru, presentan una imagen híbrida entre lo masculino y lo femenino en su vestimenta y su comportamiento; ellas gustan de mujeres, pero reiteradamente afirman que ellas no son lesbianas. De la misma manera, el tercer personaje, Marcia, asevera que ella tampoco es lesbiana, aunque por razones distintas a Elena y Maru.

El filme Boys Don't Cry relata el dilema de un transgénero de mujer a hombre, que no ha realizado su transformación corporal, pero que se siente y se comporta como un hombre, asume o reproduce una masculinidad agresiva, y se encuentra en el dilema de la aceptación social de su condición sexual y su identidad. El documental Falso orgasmo narra la historia de un personaje real, que consume hormonas masculinas y se ha extirpado los senos, pero que no 
ha eliminado su vagina. Un hombre-mujer que hace espectáculo performance, y que se considera un anarquista del cuerpo, un ilusionista del género, y que si bien es anarquista, no admite el caos.

\section{Masculinidades femeninas: del lesbianismo a la transexualidad de mujer a hombre}

\section{El viaje: de la heterosexualidad aparente al lesbianismo}

El filme Sancharram (El viaje, 2004), de Ligy Pullappally, propiamente no aborda el tema de las masculinidades femeninas, sino el lesbianismo, no obstante, el personaje Kiran asume un rol masculino que marca la ruptura entre el mundo heterosexual y lesbiano. El viaje del filme comienza con la imagen que insinúa el suicidio de Kiran, pero esta idea es metafórica. Una vez descubierta la relación entre Kiran y Dalilah, a la última se le obliga a casarse para mantener la respetabilidad de la familia, decisión que ella acepta. En contraste, Kiran llama a la rebelión contra la costumbre y la tradición, al afirmar que ellas podrían seguir viviendo como mujeres casadas, asunto que Dalilah ve imposible. En el momento de las nupcias, Dalilah se arrepiente y abandona la boda, en la puerta del templo da un grito cuyo leve eco llega a Kiran; en ese instante esta se resbala y casi cae en el precipicio.

La metáfora reside en el proceso de separación de Dalilah y la ruptura con la tradición. Por una parte, Kiran se viste con un traje masculino blanco de matrimonio y se corta el cabello; esta transformación implica la muerte o el despojo de su feminidad, por lo que, el supuesto suicidio puede interpretarse como la rotura con la manera de ser mujer según la tradición india, al asumir una apariencia masculina. Además, la escena frente al precipicio, junto con la del corte del cabello, también connota la separación que hace Kiran con Dalilah.

El filme plantea que el lesbianismo no es algo antinatural, en oposición a la voz de la madre de Kiran, quien considera que su hija (Kiran) está enferma y que ha de llevarla al médico; no obstante, Kiran responde que ella no es antinatural ni está enferma, y que renuncia al matrimonio tradicional y al "que dirán". Por un lado, el filme asevera que las costumbres son culturales e históricas, pero que no son fijas, y que estas pueden cambiar; en específico, apela a la naturalidad de la diversidad sexual o de género.

Por otro lado, se centra en la sublevación de lo que significa el amor; a este respecto la Kakathi, pronostica, sin poder asegurar, el amor entre las dos mujeres. Ella afirma que se amarán con un amor de niñez, que les llevará a conocerse a sí mismas. En este sentido, las poesías del amor no son solo un recurso heterosexual, sino que a la poesía pueden recurrir las lesbianas. El amor no tiene un destino prefijado, todos pueden participar de él. El amor para Karin es "como una noche fría y oscura,/ un día nuestro amor unirá nuestros 
cielos./ Tú y yo como luciérnagas,/ volaremos al cielo que oscurece" (PullappaIly, 2004, 53'-53:10'). El amor es como un viaje: “Te adoraré desde los valles del anorimati./ El amor me aguarda como una nube amenazada/ atascada en el horizonte lejano del viaje de mi vida, largo viaje" (53:15'-53:17'). Ese viaje consiste en la dificultad de alcanzar el amor lésbico, en un mundo de discriminación y exclusión.

Importa destacar que la homosexualidad femenina o lésbica, según Monsiváis, en razón de la superioridad que se atribuye al machismo, es lo profundamente inmencionable, y al igual que en el filme, es en la poesía en la que se hace visible ese ocultamiento, el que, en el caso de México, fue abordado por la poesía modernista (Monsiváis, 2010, 62-64).

En relación con la metáfora del suicidio, cabe aludir de nuevo a Monsiváis, ya que para él, el culto al machismo tiene como consecuencia la preocupación regocijada de lo diferente, es decir, las lesbianas no existen en el imaginario popular, solo las machorras a las que no se les adjudica vida sexual: "las lesbianas deben aportar atavíos masculinos para ser convincentes ante sí mismas y actuar, al mismo tiempo, desafiando y acatando el prejuicio" (Monsiváis, 2010, 96).

Esta misma idea de rebelión de Kiran, la proclama de Cheryl Clake, en el ensayo "Lesbianismo: un acto de resistencia" (1981). Ella considera que la lesbiana no es solo una mujer definida por sus prácticas sexuales, sino un sujeto que, al tomar conciencia de sus opciones vitales se convierte en opositora a la cultura y a la tradición discriminadora de la diversidad sexual. Esto mismo puede decirse de Kiran, ya que su sexualidad dejó de ser privada para pasar a la esfera de lo público, pero siempre en el ámbito individual, mas no en el colectivo.

\section{Amor entre mujeres: miedo al compromiso}

El filme Un amor diferente no se puede clasificar como cine queer, ya que se trata de una propuesta de normalización de la relación de pareja lésbica. Si bien en el fin hay una situación de no aceptación por parte de la familia china de Will, este rechazo es inicial, puesto que en el transcurso de la historia, la relación lésbica acaba siendo asimilada y aceptada como una situación normal.

En todo caso, la película muestra que, incluso, en las relaciones heterosexuales no todo es normal, también ocurren situaciones extrañas que no se rigen por los patrones ideales del comportamiento heteronormativo, tales como el embarazo fuera de la familia y el amor de una mujer madura con un hombre joven. La tradición y la cultura china, en el contexto de una ciudad como New York, saltan ante las prácticas sexuales. La madre embarazada fuera del hogar es rechazada por el padre de esta, hasta que no se case, lo cual se consigue, cuando ella se empareja con su joven enamorado.

La madre rechaza a Will por ser lesbiana. Will le confiesa que es gai, ella le replica que cómo puede decir algo así, pues ella no es una mala madre, por 
lo que su hija no puede ser gai, entonces, Will le responde que tal vez ella no debería ser su hija. Sin embargo, la madre finaliza admitiendo la situación del matrimonio lesbiano, e incluso, reclamando la pronta familia. Además, la sociedad china de Planeta China, asimila la situación, en especial, cuando Will y Vivian se encuentran en el salón de baile y comienzan a danzar.

El filme contiene un aspecto interesante, ya que se trata de una relación lésbica en la que se expresa un juego de roles femenino-masculino. Por un lado, a Vivian se le presenta como una lesbiana femenina, y a Will como una mujer lesbiana que viste como hombre. La madre de Will se queja de su manera de vestir, ella prefería que su hija vistiera como una "mujer"; mientras que la abuela defiende esa manera de ataviarse, ya que tal vestimenta es más apropiada para realizar ciertas acciones. Por otro lado, el rol masculino que se le asigna a Will, por lo general, se consigna como parte del comportamiento de los hombres, tales como el miedo al compromiso y al matrimonio.

A Will no se le recrimina por vestir como hombre, esta es una situación contraria a la descrita por Monsiváis en el caso de las lesbianas mexicanas (aunque es probable que se aplique al caso de Costa Rica) en que:

El mundo de las lesbianas mexicanas en la primera mitad, ocultado por el prejuicio y la incredulidad que iba más allá de los prejuicios ¿Cómo era posible? Mujeres que se entienden entre sí, sin la necesidad de los hombres. El lesbianismo era tan inconcebible que a sus practicantes se les vilipendiaba por el aspecto de 'marimachas' o de 'quedadas profesionales', y no por la conducta que la sociedad se negaba a creer posible. Así a las maestras de invariable traje sastre, a las activistas políticas de corte férreo, a las solteronas que amistaban románticamente con jovencitas, se les hostilizaba por no ser femeninas, y ser agrias y severas, pero no por ejercer su sexualidad (Monsiváis, 2010, 201-202).

Según Mark Mondimore, en el siglo XIX, a la mujer masculina se la consideraba patológica, mientras que a la lesbiana "femenina" se la describía como perversa (Mark, 1996, 86). Así, Will no es discriminada por vestir como hombre, sino por ejercer su sexualidad, aunque ella inicialmente se oculta, vive su relación a escondidas, por ejemplo, nunca sale con Vivian, no conoce a sus amigos(as), no abandonan en el apartamento y no pasan la noche juntas. Pero una vez que sale del armario, es cuando puede notarse la razón de la no aceptación: su práctica sexual. Esto implica un cambio significativo en lo narrado por Monsiváis y el filme, ambos describen épocas distintas.

Sin embargo, Beatriz Gimeno, una dirigente lésbica española, tiene una opinión diferente sobre visualización de la lesbiana; ella indica que:

Como las lesbianas son invisibles, se salvan de los aspectos más agudos de la hostilidad contra los homosexuales. Por ejemplo, nunca ha habido leyes contra las lesbianas y sí contra los homosexuales masculinos. La otra cara de la moneda es que al no existir oficialmente las lesbianas, cuando las cosas mejoran, es decir, en las democracias, cuando hay más tolerancia y sensibilidad 
hacia el problema homosexual, las lesbianas se quedan al margen de los posibles avances legales o sociales (Gimeno, 2010, citado en Cristóbal, 120).

Sin embargo, este último no parece ser el escenario del filme comentado

\section{Butch o Trailera: "estamos hablando de hombre a hombre"}

El filme Gazon Maudit, de Josiane Balasko, inicia con un juego de palabras para nombrar la realidad de la diversidad sexual del lesbianismo, esto cuando Marie-Jo compara el término sofá con Safo, para luego remitir al título del filme con el concepto de felpudo, que connota a vagina, a la cual, también nombra como el conejo. En relación con la vagina también hay otro juego de lenguaje, que parece referir a una vagina grande; esta metáfora es la del castor tiene cola. También, alude a las lesbianas con el término español de bollos, cuya expresión análoga en Costa Rica sería tortillera.

El filme es ambiguo en el uso de estos términos, ya que si bien MarieJo tiene una apariencia masculina y se comporta como un hombre, también parece identificarse con una bollera, aunque el título connota negativamente, pues la traducción al castellano sería algo así como maldito felpudo. Mientras que por una parte Marie-Jo se identifica como hombre, por ejemplo, en la discusión que tiene con el esposo de Lola, por saber a quién "pertenece" Loli, él reconoce a Marie-Jo como un hombre. También, cuando Marie-Jo llega por primera vez a la casa de Lola, y el hijo, Julián, la mira y la identifica como hombre; del mismo modo, Lola ratifica esta ambigüedad aclarando que no es un hombre. Sin embargo, a veces se resalta que Marie-Jo es una lesbiana masculinizada, pero también, se indica su actitud masculina de protección a la que considerara a su pareja: Loli. La indeterminación se sostiene cuando el esposo de Loli reta a Marie-Jo a pelear, y le dice "juegas a ser tío [hombre] y te da miedo salir", Loli le dice a su esposo, que cómo le va pegar a una mujer y el indica "dónde vez a una mujer" (Balasko, 30:31'-30-35'). Asimismo, Marie-Jo no renuncia a su capacidad biológica de reproducción, y desea tener un hijo del esposo de Lola, y si bien ambos muestran su incompatibilidad y repulsión, acuerdan pensar en su objeto de deseo para poder tener el contacto sexual.

Esta situación sirve para ilustrar la guerra de los términos para referirse y nombrar la realidad de la diversidad sexual y la identidad de género. Pero esta guerra de los nombres no es banal y antojadiza, puesto que los términos, depende de donde provengan, reflejan la opresión o la liberación. Además, son etiquetas que sirven para crear un sentido de identidad y segregan la realidad compleja de la homosexualidad y la diversidad sexual. Igualmente, sirven para incluir o excluir a personas que pertenecen al grupo y para discriminar; recuérdese que la identidad se conforma diferenciándose del Otro y nombrar las diferentes opciones, o la diversidad sexual, o de género, son maneras de distanciarse del Otro. 
En la película Gazon Maudit, no queda claro si Marie-Jo es un transgénero de mujer a hombre o una lesbiana masculina, ya que realmente en este personaje existe un cruce de géneros; a este tipo de butch-femme es lo que Halberstam calificará como género queer. Para ella, la gente queer es rechazada, incluso por aquellos teóricos que hablan de la construcción del género porque se sigue "manteniendo la sospecha sobre la masculinidad en las mujeres, y que existe una confusión generalizada sobre el sentido de la rigidez y la flexibilidad del género" (Halberstam, 2008, 12). Aunque, la verdad no se entiende en qué sentido el género puede ser tan flexible, salvo algunos casos excepcionales. Lo que sí comparto con Halberstam es la idea de que la identificación con el otro género genera desconfianza, así por ejemplo, ella considera que algunas investigadoras explican las identificaciones transgénero de mujer a hombre como algo que es causado debido a la ausencia de un contexto femenino (Halberstam, 2008, 12), es decir, se trata de una desconfianza feminista hacia la masculinidad (Halberstam, 2008, 13). Para la crítica feminista, los comentarios relacionados a las mujeres que cambian de género se basan en un prejuicio, y esto se debe a que han puesto énfasis en los estudios de las lesbianas, y han invisibilizado a los transgénero masculinos. Además, ser una transgénero masculino es caer en la trampa del patriarcado, según ciertos estudios feministas.

Halberstam escribe sobre mujeres que se sienten más masculinas que femeninas, y se queja de lo poco que se ha escrito sobre este tema; para ella, las mujeres masculinas deberían vivir su masculinidad sin estigma, sino más bien con orgullo o incluso, poder (Halberstam, 2008, 19). Ella considera que su libro es un ataque al prejuicio que mantiene la idea de que la masculinidad es un privilegio exclusivo de los hombres. Y es que Halberstam testimonia que "yo era una chica masculina, y soy una mujer masculina. Durante la mayor parte de mi vida, las críticas a mi ambigüedad de género han convertido mi masculinidad en algo vergonzoso. Sin embargo, en los últimos diez años he sido capaz de convertir mi estigma en algo que me fortalece" (Halberstam, 2008, 19). Para ella, la masculinidad

no es la expresión social, cultural ni política de la virilidad [...], no debe y no puede ser reducida al cuerpo del hombre y a sus efectos [...] a pesar de todo, socialmente tenemos pocos problemas en reconocerla, y de hecho invertimos mucho tiempo y dinero ratificando y consolidando las versiones de masculinidad que nos gustan y en las que creemos. Muchas de estas 'masculinidades heroicas' se basan fundamentalmente en la marginación de las masculinidades alternativas [...], las masculinidades femeninas se consideran las sobras despreciables de la masculinidad dominante, con el fin de que la masculinidad de los hombres pueda aparecer como lo verdadero (Halberstam, 2008, 23). 


\section{Familia Queer: "un hogar normal de lesbianas" o transgénero}

En el filme Two Girls in Love, de Maria Mangenti, se presentan dos situaciones interesantes de normalización de la familia y pareja queer o lesbiana. Aunque la idea de la normalización del matrimonio, la familia y la pareja, no es un tema queer propiamente dicho, los personajes y las situaciones del filme lo son. Al respecto, primeramente puede indicarse que existe una tendencia en el movimiento queer a rechazar la normalización del matrimonio y la familia homosexual, y queer, por tratarse de algo conservador y legitimador del sistema heteronormativo. Segundo, por lo general, una parte del movimiento queer optaría por el aislamiento del sistema o reivindicaría un cambio radical del sistema, cosa que no sucede en el filme, sino que este se ubica en una perspectiva de reconocimiento; por tanto, esto hace que el filme no pueda ser considerado como queer.

En contraste, el filme es un esfuerzo por lograr la aceptación y la asimilación de la pareja y la familia queer. En este sentido, se contextualiza la intención de Randall Dean por mantener la relación con Evie, esto a pesar de las dificultades que enfrentan; sin embargo, el filme llega a un final feliz y a una pareja consolidada por el amor. Luego, se representa a una pareja de mujeres en roles masculino-femenino o butch-femme, consolidada, en cuya casa se exhibe una bandera gai, y una voz de tercera persona, indica que se trata de "un hogar normal de lesbianas" (Mangenti, 3:01'), un hogar conformado de manera no tradicional, ya que no se trata de una pareja hombre-mujer heterosexual, sino una mujer "lesbiana", con una mujer masculina o butch -aunque se parece más a un transgénero- este último es la "tío" de Randall. Además, con la familia vive una amiga.

El filme se muestra ambivalente en relación con el tipo de masculinidad de Randall y la tía, ya que si bien ambas visten como hombre, asumen roles masculinos y ejercen trabajos masculinos. A este respecto, la tía siempre aparece con su trabajo de mecánico y Randall asume el comportamiento de un adolescente. Sin embargo, en el filme nunca se manifiesta si estos personajes se refieren a sí mismos como hombres, se asumen como tales o si son transgéneros, aunque, las imágenes, de manera clara, evidencian que se trata de personas transgénero, las que son asumidas por parte del espectador como hombres. A pesar de esta lectura, la que puede hacerse desde una tercera voz, el filme juega con la ambivalencia de los personajes, es decir, con certeza no puede afirmarse si son transgénero o si simplemente su masculinidad es una manera de sobrevivencia lesbiana o si lo que se plantea es una manera diferente de presentar la masculinidad femenina sin necesidad de la intervención de los hombres, de tal manera que esta no siga el patrón machista de la sociedad heteronormativa.

Por su parte, Randall manifiesta que la "vida es algo áspera por fuera [...], yo vivo en el presente, no pienso en el futuro, el futuro es impredecible" 
(Mangenti, 2:50'-2:53'); esto supone su peculiar orientación sexual no es llevadera, además, porque "el amor es difícil" (Mangenti, 11:52'). También, porque su apariencia masculina conlleva discriminación, ya que por una parte en la escuela se le considera una lesbiana, y se le ofende con el insulto de "maldita lesbiana", y por otra, se indica que ella es "muy rara, en muchos sentidos" (Mangenti, 15:35'), es una "lesbiana que hace de macho [...] debería cuidarse, no tratar de actuar como un hombre" (Mangenti, 23:42'-23-43'). Otrosí, su madre la desprecia por "pecadora". Es claro que Randall se sale del marco de lo que se considera debe ser un hombre o una mujer, así, su manera de expresar el género resulta incomprensible y es visto como anormal.

Sin embargo, existen algunos indicios de que el narrador en tercera persona resalta que Randall es un transgénero: primero, en un encuentro de Randall con Evie, en la estación de servicio, éste lleva una camisita en la que se lee "Your body is a battleground" (Tú cuerpo es una lucha... por crecer) (Mangenti, 32'). Asimismo, del libro de poesía de Walt Witman, Hojas de pasto, que Evie regala a Randall, lee la poesía intitulada "Yo canto al cuerpo eléctrico" (49.12'). Ambos indicadores remiten a la ambigüedad o la transformación del cuerpo; de hecho, una frase de la poesía indica que tanto el hombre como la mujer devienen del cuerpo femenino. Luego, Randall afirma que "se me acusa por lo que nunca tuve" (53:04'). Esta última frase, en el contexto del filme, deja en evidencia que Randall vive en una situación turbia, ya que puede interpretarse que desde el punto de vista biológico es mujer, pero que desde su perspectiva de género es un hombre; no obstante, ambos aspectos en combinación producen una situación que no es fácil de descifrar o codificar, porque no se ajusta a las normas. Pero lo curioso es que si se hace caso de lo que dice la camiseta, su cuerpo está en transformación, y tomando en cuenta la poesía dirigida, podría considerarse que Randall es un transgénero de mujer a hombre.

Ahora, este mismo deseo cognitivo de saber quién es Randall, implica una obsesión por clasificar el género de dicho personaje, pero esto también advierte de lo que en el enfoque queer se ha dado en llamar la guerra de las fronteras. Y aquí se encuentra una paradoja, pues si bien la teoría queer se declara anti-esencialista, en los textos siempre aparecen debates intensos sobre los términos usados para referirse a la diversidad sexual y de género; del mismo modo, existen muchas disputas sobre cómo clasificar esa realidad y saber qué es lo que entra y no entra en los conceptos. Es entonces, que mientras que unos teóricos tienden a establecer realidades estancas y discontinuas, otros hablan de zonas grises, no clasificables, las que incluso, no calzan en las categorías establecidas por el movimiento gai, lesbiano y trans. Entretanto que algunos teóricos prefieren utilizar términos universales para referirse a esa diversidad de la realidad sexual y de género, como el caso del término queer o gai, otros teóricos(as) prefieren términos diferenciadores porque los universales tienden a ocultar las diferencias. 
Pero es claro que estos debates son ontológicos y epistemológicos; todos, de alguna forma u otra, remiten a un tipo de esencialismo y a intentos de fijar los géneros y los sexos o marcar zonas de transición. Incluso, en el caso del filme, si bien juega con la ambigüedad, la iconografía que utiliza hace una lectura de la identidad de género y de la sexualidad de Randall y la tía, que fija su condición sexual.

Es cierto que las condiciones sociales, culturales, económicas e ideológicas han cambiado mucho con el paso del tiempo; estas transformaciones han hecho posible que nuevas realidades entorno a la pareja gai, lesbiana, transgénero y la transexualidad emerjan a partir de los nuevos contextos. Es así, que existe una intensa discusión en los estudios gais, lésbicos y queer sobre si las realidades de la diversidad sexual del pasado son iguales a las actuales, o si lo que hoy se considera homosexual es lo mismo que en tiempos anteriores. Y por tal motivo, es que a veces se piensa que cuando se crea un concepto se está instaurando la realidad, pero por lo general, sucede que la realidad social ya está ahí como fenómeno, pero sin un nombre para designarla. Ahora, el otorgar una etiqueta tiene consecuencias, por ejemplo, en el caso de la diversidad sexual, las etiquetas sirven para elaborar la identidad, y el nombrar el hecho influye sobre el mismo hecho social.

Si bien, y a pesar de que, la pareja y la familia lesbiana y queer es novedosa en tanto fenómeno de identidad de género; sin embargo, según Halberstam, realmente no lo es. Esta autora asevera que pueden encontrarse situaciones de mujeres masculinas con relaciones de pareja o amantes en la historia: estas mujeres masculinas aparecen "como alguien que ya estaba en la historia, como un personaje que ha desafiado los sistemas de género durante al menos dos siglos" (Halberstam, 2008, 67). También Mondimore refiere a otros casos de mujeres y de relaciones semejantes. Para Halberstam, las interpretaciones que solo ven fenómenos completamente novedosos sobre la diversidad sexual implica una visión ahistórica de la evolución de la diversidad sexual y de género (Halberstam, 2008, 67).

En el caso de la mujer masculina, dice Halberstam que estas "han desempañado un papel importante en la construcción de la masculinidad moderna" (Halberstam, 2008, 68). Para ella, a estas primeras formas de masculinidad femenina se les identificó como lesbianismo, pero realmente tal identificación, les priva de su identidad histórica (68). Además, relata la historia de mujeres masculinas que establecieron sus relaciones de pareja, aunque a veces estas relaciones son con amantes casadas (79). Este es el caso de los diarios de Anne Lister, quien se hacía pasar por hombre para poder ligar con mujeres. Halberstam para referirse a estos casos de pareja, utiliza el término marido mujer, es decir, "mujeres que se hacían pasar por hombre con el fin de casarse con mujeres que habían sido abandonadas o repudiadas por sus maridos varones" (Halberstam, 2008, 90). Por supuesto, estos casos difieren de la pareja lesbiana 
actual, pero también indican otras maneras de establecer esas relaciones, las que se acercan más al tipo presentado en el filme Two Girls in Love.

\section{La transexualidad: el dilema no deseado}

El filme Boys Don't Cry (1993), de Kimberly Peirce, se cataloga explícitamente en la categoría de cine queer, en contraste con las otras películas. A pesar de esto todas ellas abordan temas queer, las que este enfoque dice rescatar del olvido, ya sea por parte de la sociedad heterosexual, el movimiento feminista o los grupos homosexuales. Es entonces que, en cuanto a dichas materias: la transexualidad, el transgénero y la intersexualidad, Boys Dorit Cry no marca mayor desavenencia. El punto de inflexión del filme reside en que el personaje principal, Brandon, no tiene que demostrar su honorabilidad para ser asumido como un relato que denuncia la situación de discriminación y odio hacia estas minorías de la diversidad sexual.

Brandon es un joven que asume una identidad de género masculina agresiva: busca la confrontación violenta en los bares (en principio para defender lo que considera injusto), se adhiere a los juegos bravucones (para mostrar su masculinidad), hurta, violenta la ley en pequeños detalles y ha estado en prisión por su conducta no adaptada a las normas de civilidad y convivencia. Brandon es un personaje al margen de ley. Además, gusta de la aventura y el riesgo. Este personaje es un hombre que si bien intenta mostrar una virilidad enérgica, tal y como lo retrata el filme, él no es un muchacho tan viril, pues se ve débil, poco fornido y de facciones finas. Si bien el filme es de tendencia queer, en este no se cuestiona dicha masculinidad, sino que se asume como algo "dado".

Este filme también es queer porque se mantiene en clave dramática, no suaviza ni ridiculiza al personaje ni al contexto, a diferencia de Transamérica, en donde se combina el drama con la comedia; sino que la narración termina con una muerte infausta, lo cual, se debe al hecho de estar contando una historia real, por lo que, el filme es un documental.

Aunque la película se ubica en clave de la teoría queer, esta intenta justificar la disforia de género de Brandon, no desde un cuestionamiento explícito de la construcción social del cuerpo y el género, o de una perspectiva lingüística preformativa, sino a partir de las bases biológicas que produce la "crisis de identidad sexual". La película es la narración de un transexual de mujer a hombre que, además, es heterosexual. Brandon atribuye esta situación a un problema de nacimiento, algo que no puede controlar; él nació en un cuerpo femenino pero tiene una mente masculina. Cuando Lana pregunta si él antes era ella, Brandon responde que al principio era femenina, luego fue como una chica marimacho, y después, se volvió un estúpido. Esta última frase, tal vez no refiera a su condición de género, sino a su conducta disonante, pero lo cierto es que Brandon asume su condición de transgénero, ya que él no ha iniciado el proceso de cambio de sexo. Aunque, la transexualidad 
para algunos autores, puede incluir a aquellas personas que no desean la transformación de su cuerpo.

Sin embargo, en una de las escenas, Brandon, para justificar ante Lana el por qué se encuentra en la prisión de mujeres, afirma que es un hermafrodita y que cuenta con los dos órganos genitales: masculino y femenino. No obstante, la narración lo que presenta es a un Brandon en desdoblamiento, escindido, es decir, una identidad que no logra armonizarse: en el que existen dos seres. Él dice a Lana, que Brandon es en realidad Teena, que "Brandon no es del todo él. Brandon más bien es ella" (Peirce, 1:12.18'). Tal vez esta sea la relación con el "hermafrodismo" (1:12') que se establece en el filme. Esta disensión se presenta en la escena en la que la Teena se ve reflejada como Brandon, esto ocurre cuando en el baño de la casa de Lana, Lotter y Tom intentan verificar la genitalidad de Brandon. Es así, que cuando Lotter, de manera forzada, comienza a desvelar la identidad biológica de la hembra que anatómicamente es Brandon, Teena en ese momento, se ve a ella misma, en el otro extremo de la habitación, en su auténtica identidad como hombre. El recurso fílmico es interesante: una imagen de Brandon masculino que aparece entre los rostros de las otras mujeres.

Esta imagen reflejo, que divide la personalidad de Brandon, contrasta con la propuesta de Transamérica, la cual plantea la unidad de la identidad de Bree, en especial, cuando ella habla a la psiquiatra de la existencia de su hijo, al cual refiere como el hijo de Stanley en tercera persona. La psiquiatra le indica que se remita a Stanley en primera persona, ya que, su pasado masculino es parte de lo que Bree es ahora, y que su historia biológica no la puede negar, ni mucho menos los frutos de su historia de vida.

Otro asunto sugestivo de este filme es que recurre a un manual que explica la condición transexual, se trata del texto Travestismo y transexualidad: el dilema no deseado, del cual se toma el título de este acápite. Esto es comprensible, ya que para la mayoría de las personas la transexualidad, el transgénero y la intersexualidad no resultan comprensibles desde el sentido común, por lo que se requiere una inducción o elucidación de las situaciones en la que se encuentran estas personas. Al público se le han de exponer las razones o las causas de la existencia de dicha realidad de la sexualidad humana.

El filme no puede dejar de expresar la necesidad de realizar el cambio de sexo. Brandon, en una conversación con su primo Lonny, cuenta dicho proceso: "mi vida es una locura. Tendría que ir a un matasanos e inyectarme hormonas en el culo. Cuesta una fortuna. Me haré viejo antes de juntar todo ese dinero" (Peirce, 12:21'-12:28'). Mientras que en Normal, se explica cómo se convierte un pene en una vagina, en Boys Donit Cry, se esboza una explicación de cómo se construye un pene: "el injerto de piel imita la piel del pene natural" (1:16:20'). De nuevo es recurrente la idea de que la ciencia y la tecnología son las vías para resolver el dilema no deseado. Tampoco, el filme asume que el 
género de Brandon es una construcción social, sino indica que se trata de un proceso biológico y psicológico por el que transitan los transexuales; un proceso de reconocimiento y elaboración de su identidad sexual y de género.

En una de las primeras escenas, unos hombres persiguen a Brandon y le gritan que es "una enferma, una maldita tortillera, una anormal, una marica y una lesbiana" (Peirce, 5:57'-5:58'). Posteriormente, Brandon relata a su primo Lonny su incertidumbre al no saber qué salió mal en su intento de establecer una relación amorosa con Nicole. Al respecto, Lonny le dice, "no eres un varón, eso es lo que sucedió. No eres un varón ¿Por qué no admites que eres una lesbiana?" (5:59'-6:02), y Brandon replica: "porque no soy lesbiana” (6:12'), con lo cual, se rectifica la condición heterosexual de Brandon. Pero aquí se resalta la idea de la confusión común entre el lesbianismo y el transexualismo de mujer a hombre.

Si bien al inicio del filme a Brandon se le presenta como un monstruo, en el trascurso de la narración deja de ser una persona anormal para convertirse en un mentiroso. Al igual que en Transamérica (2005) de Duncan Tucker, a Bree, un transexual de hombre a mujer, se le señala como una mentirosa, por ocultar su identidad. Ambos filmes coinciden en un llamado a salir del armario, y mostrarse tales cuales son. Esta es una política de la identidad que se atribuye tradicionalmente al movimiento homosexual denominado asimilacionista, ya que promueve la integración al sistema sexo/género, esto según como lo expone Laurentino Vélez-Pelligrini (2008). Una política que no resulta extraña en Transamérica, pero sí en Boys Don't Cry, ya que en este último se dispone en perspectiva queer, cuya política es la salida al espacio público de manera colectiva, como en el caso del grupo Act-Up, que en su lucha contra el VIH/ SIDA, acuña la consigna todos somos seropositivos.

Por último, como ya se ha indicado, la investigación sobre las masculinidades femeninas es un tema olvidado, el cual ha sido recuperado por los teóricos (as) queer. A este respecto Halberstam reconoce que las masculinidades son parte de la identidad de las mujeres queer, y que existe una gran diversidad de masculinidades femeninas (Halberstam, 2008, 9), como se muestra en este artículo. Ella denuncia que el hecho de que este tema sea poco estudiado, se debe al rechazo patriarcal que provoca -tanto de las mujeres heterosexuales como de algunas feministas- la imagen de mujeres con aspecto masculino (8). También, considera incomprensible el rechazo entre las lesbianas blancas cultas de clase media (9) hacia las mujeres masculinas.

\section{Masculinidades queer: sin palabras, sin fronteras}

El título del acápite ubica a las palabras como límites de las fronteras de la identidad. En el filme Tan de repente se presenta una peculiar iconografía de la "lesbiana" o el transgénero queer, es una de la más originales de las películas analizadas en este artículo. Se trata de dos mujeres con estilo de cabello corto 
que conforman un híbrido entre lo masculino y lo femenino; ambas visten con botas militares, con camisetas o chamarras, y una de ellas lleva una enagua de cuero corta; mientras la otra viste un pantalón corto tipo militar. Las dos mujeres dan una sensación de dureza, no obstante, sus facciones físicas y su rostro no reflejan la brusquedad de un hombre. Esta mezcla marca una construcción de una peculiar identidad masculina, pues no se trata de la típica imagen de la trailera, como es el caso de Marie-Jo. A este respecto, la iconografía y el concepto que se refleja en estos personajes, a veces resulta poco interpretable (en la lectura del fenotipo), en razón de la ambigüedad o por los lindes difusos en los que se mueven.

Además, estas mujeres se muestran como delincuentes que roban, abusan y secuestran. En este sentido, el filme no se ubica en la idea del gai, la lesbiana o la gente queer que tiene que aparecer como respetable para hacer valer su identidad, sino que estas personas resultan odiosas y repulsivas; ellas están fuera de la ley. Por tales motivos, el enfoque de la película se acerca más a una perspectiva de cine queer. Sin embargo, el filme no es maniqueísta, sino se introduce una perspectiva humana en los personajes principales: Elena (Verónica) y Maru. Según esta idea, la película es una historia de soledades, abandonos, falta de perspectivas, de vivir al día, de zona de existencias grises, de complejidad de roles de género, de tristezas, desolaciones y calamidades existenciales.

Por otra parte, la película utiliza el formato de un viaje de camino, en donde tres mujeres ocupan el espacio de lo público dedicado a los hombres. Tomando en cuenta lo anterior, se puede afirmar que el filme tiene otra característica que la ubica en perspectiva feminista: si bien, puede considerarse que tanto Verónica y Maru son personajes transgénero, tal perspectiva podría contradecir el enfoque de la liberación de la mujer, y, más bien, podría ubicarse el filme en una perspectiva conservadora, ya que reproducen los roles masculinos. Este es el dilema que Halberstam expone claramente en el caso de la transexualidad masculina. Para algunos(as) teóricos(as), la transexualidad es esencialmente transgresora, mientras para otros(as), es un conservadurismo de género. Ella piensa que realmente no se trata de ni uno ni otro asunto, sino que, más bien, la define como una política de la identidad transexual y transgénero como esencialmente contradictoria (Halberstam, 2008, 185); por lo que, el filme puede leerse en esta clave paradójica. Este panorama queda reflejado en el nombre de la barca: Sinpalabras.

Ahora, la idea de lo transgénero de los personajes, se refuerza con la reiterada insistencia de Maru en negar que es lesbiana. Si bien, Marcia, una mujer heterosexual, también niega su lesbianismo; es por lo anterior, que en la lectura que aquí se hace, este hecho no parece contradecir la declaración de lo transgénero de Verónica y Maru, ya que la relación entre Marcia y Maru puede interpretarse como una correspondencia entre una mujer con identidad masculina y una mujer heterosexual, o en todo caso, una lesbiana femme. Sin embargo, esto no obvia otras lecturas. 
La única situación que podría entrar en negación con este análisis, es la relación que establece Maru con Felipe. Pero en todo caso, esto puede verse como una manera más de diluir los límites de las fronteras entre los géneros normativos de lo masculino y lo femenino. Asimismo, hay otras situaciones de menor envergadura que también marcan los límites imprecisos de las fronteras de los géneros; esto tiene que ver con el intercambio del vestuario forzado, que hace Maru con Marcia.

En relación con esto último, llama la atención que en el filme se ofrece un espectáculo de performance Drag King, (mujeres artistas que se visten masculinamente y personifican roles masculinos) en donde la tía de Verónica, Blanca, se viste como una cantante ranchera femenina pero imita la voz de un hombre, en un juego andrógino. Esta escena bordea en las fronteras de los géneros, como un híbrido más de las combinaciones en que oscilan los dos géneros dominantes: masculino y femenino. Luego, otro elemento de interés, es el cuento de la mujer masculina.

\section{La guerra de las fronteras de la identidad diversa}

Un aspecto polémico relativo a la diversidad sexual consiste en el establecimiento de los límites conceptuales entre homosexualidad, transgénero y transexualidad. La visión común en el discurso o el imaginario popular es considerar que homosexual es sinónimo de transgénero o transexual, es decir, se piensa que una persona con cuerpo masculino y comportamiento femenino o una con cuerpo femenino y comportamiento masculino es la expresión extrema de la actuación o condición homosexual. Así, se crea el estereotipo que alimenta la idea de que los gais y las lesbianas son invertidos y que asumen por completo el género contrario.

También, desde un punto de vista científico, inicialmente, se consideró que estas tres maneras de ser y hacer, así como sus formas de conducta eran lo mismo, hasta que la evolución de dicho conocimiento estableció las diferencias. De la misma forma, en un sentido coincidente, el movimiento gai y lesbiano, comenzó a diferenciar entre las tres categorías, dando como resultado que en la actualidad, tanto desde el punto de vista científico como desde el movimiento gai, lesbiano y transexual, se establece la diferencia. Por lo general, se indica que la persona homosexual (gai o lesbiana) tiene como objeto de deseo a una persona del mismo sexo y género, y por tanto, no se siente del sexo contrario. Mientras, que el(la) transexual es una persona que siente deseo por el sexo contrario, pero tiene un cuerpo que no le corresponde. Frecuentemente, estas personas no son homosexuales, sino que se trata de personas con cuerpo hembril que se sienten hombres y gustan de las mujeres o se trata de personas con cuerpo machil, que se sienten mujeres y que prefieren a los hombres.

Además, las personas transexuales han comenzado a cambiar sus cuerpos, por medio de la tecnología hormonal o la cirugía; junto con el cambio de 
la vestimenta y la apariencia física. Ahora, según las estadísticas o los casos conocidos, son pocas las personas transexuales que, una vez transformado su cuerpo, se declaran lesbianas o gais.

Por otra parte, con la aparición de las tecnologías de la modificación del cuerpo, surgen situaciones nuevas que requieren de nuevas categorías, es el caso del transgénero, el cual es considerado por los enfoques queer más recientes como aquella persona que no ha producido un cambio hormonal ni quirúrgico. Para algunos autores, se trata de una etapa a la transexualidad; estas son pues personas cuyos cuerpos, hembril o machil, visten, se comportan y sienten como el sexo contrario.

\section{Los espacios territoriales y el continuo de las masculinidades}

La metáfora de la guerra sobre las fronteras o espacios territoriales fue acuñada por la teórica queer Gayle Rubin, una antropóloga que se dedica a estudiar la cultura leather, y se convierte en una activista. El término lo acuña en 1984, en el ensayo "Reflexionando sobre el sexo: notas para una teoría radical de la sexualidad". El se concepto refiere a "los procesos por las que ciertas minorías eróticas crean comunidades y las fuerzas que tratan de reprimirlas conducen a luchas sobre la naturaleza y las fronteras de esos territorios sexuales" (Rubin, 1984). Halberstam utiliza el concepto para delinear los debates académicos sobre los lindes de las fronteras y las zonas difusas de las identidades sexuales y de género.

Para esta última autora, las categorías están en constante construcción; esta apreciación no parece relevante epistemológicamente, ya que resulta obvio que los conceptos se encuentran en constante revisión, precisión y cambio, en tanto intentan representar la realidad. La filosofía de la ciencia ha mostrado este punto. Afirmar que los conceptos son construidos es algo admisible sin mayor dificultad. Pero, esa admisión es muy diferente a la posición teórica que asevera que el género, el cuerpo y el sexo son una construcción social.

Al respecto de la guerra de las fronteras, Halberstam argumenta que a los transgénero y transexuales masculinos se les ha invisibilizado al incluírseles en la historia del lesbianismo. Además, esto se refuerza porque las mismas butch duras y transgénero prefieren participar en comunidades lesbianas. Pero incluso, en el modelo del continuo masculino de Halberstam, tampoco quedan claros los lindes entre unos y otros territorios. No obstante, en relación con este argumento, parece que un asunto más común, es identificarse con las féminas y desear a otras mujeres (lesbianismo), a que una mujer se identifique con el género masculino y desee mujeres en tanto que se asume como hombre. Pero lo que señala Halberstam, es que existen puntos medios: las zonas grises en las que no están claros esos límites. 
Esta autora expone el rechazo que las feministas lesbianas tienen hacia las traileras o stone butch, los transgénero y los transexuales masculinos. Una crítica afirma que el patriarcado interviene en las mentes de estas mujeres, y que por ello, reproducen la misoginia de los hombres; otras veces, se les ve como traidoras, al asumir el género de la opresión; esto, entre otras críticas.

Pero, en todo caso, una de las ideas más relevantes de Halberstam, es que las masculinidades femeninas son una manera de teorizar la masculinidad más allá del cuerpo del hombre y de su virilidad $(2008,36)$. En este proceso de conceptualización y de prácticas, existen muchas variantes de masculinidad femenina. A este respecto, los cuerpos de la masculinidad femenina son ambiguos en sus relaciones funcionales.

El libro de Halberstam presenta un modelo de un continuo de la masculinidad femenina (176), este modelo va de lo no masculino a lo masculino, de lo lesbiano a lo transexual. Su representación es:

\section{andrógino-butch suave-butch-butch dura-butch transgénero-FTM No masculino \\ Masculino}

Según el modelo, las tres primeras categorías son asumidas por mujeres lesbianas, ya que el uso de algunos aspectos masculinos no significa una identificación como hombre, y tan solo puede ser un elemento de transgresión o un juego de roles. El punto de inflexión es la butch dura, porque está en el límite entre el lesbianismo y el tránsito a la transexualidad; esta es una zona gris o difusa, puesto que es un punto en el que las diferencias están poco precisas. La butch transgénero es un término que acuña se para referir al transgénero de mujer a hombre; esta es una etapa previa a la transexualidad. Por último, la FTM es el transexual de mujer a hombre, en el que la mujer desea que su cuerpo se adapte a su yo de género; aquí hay una identificación con el género masculino. Por lo general, los FTM son heterosexuales (Halberstam, 2008, 178).

Lo que dice Halberstam, a pesar de su insistencia en lo borroso de las fronteras, es que hay territorios que están claramente marcados; no obstante, también existen transiciones entre fronteras que son difusas. Pero este modelo no parece significar que el género sea completamente flexible, puesto que como se verá, en múltiples ocasiones, existen limitantes biológicas, neuronales, psíquicas y sociológicas que no permiten, o son restrictivos de tal flexibilidad de género. 


\section{El conflicto de las fronteras y el imposible equilibrio}

\section{transexual}

Sin embargo, a pesar de esta demarcación conceptual de la realidad, en la que se delimitan zonas de identidad de ciertos grupos de personas, no existen lindes claros en los territorios seguros de las categorías, ya que, hay unas zonas grises, en donde se ubican personas que no logran calzar en las categorías establecidas. Este es el caso del perfomance Larzo Pearlman, en el documental Falso orgasmo, quien a partir de su trabajo artístico y la explicitación de su cuerpo y de su género, intenta mostrar que no existe una identidad fija, ya sea de género o sexual.

Según Pearlman, él podría considerarse como un transexual, pero como no ha completado la transmutación de su cuerpo, no es tal, de hecho, en uno de sus escenificaciones, el público le increpa porque no tiene pene. También afirma que podría considerarse como una mujer que se ha cortado sus pechos, pero que además tiene barba y pelo en pecho. Otrosí, puede tratarse de un hombre con un interés oculto, que cuando se quita la ropa en el espectáculo, se nota que hay algo escondido; no obstante, con lo que quiere indicar que hay otras posibilidades. Sin embargo, el público le pregunta si se siente artificial al verse al espejo y mirar que no eres una mujer completa o un hombre completo. A lo que responde con una pregunta retórica ¿qué es lo real? También es interrogado con la pregunta: ¿te sientes completo contigo mismo, tanto como persona como psicológicamente? Las preguntas se dirigen a por qué no se decanta por ser hombre o ser mujer, por qué prefiere quedarse en ese punto medio. Su respuesta es de nuevo otra pregunta: ¿por qué hay que pensar en disjuntos?

Claro, no es fácil entender el caso de Pearlman, pero sí lo es el de otras personas que no lograron su transformación, no porque no lo desearan, sino porque materialmente resulta imposible; es el caso de una transexual que conocí en las reuniones de CONCASIDA ${ }^{3}$ (San José, Costa Rica, 2011). Ella nunca logró completar la transformación de su cuerpo porque no contaba con el dinero suficiente, luego porque fue diagnosticada seropositiva, y no pudo seguir tomando hormonas porque estas eran incompatibles con el tratamiento para el $\mathrm{VIH} /$ Sida. Esta persona queda en una zona incierta, en donde ya no tenemos un nombre para su condición, aunque para Coll-Palmas aunque no hubiese completado su transformación sería considerado un transexual por su deseo de modificar su cuerpo.

Si por un lado, Pearlman se presenta como una actitud política, por el otro, se enfrenta a la realidad. Mientras que el primero indica que la voluntad es la que, supuestamente, controla el cuerpo y el género; en el segundo, es la realidad la que marca los límites a la transformación del cuerpo y no la voluntad. 
Según Coll-Planas, el caso de las personas transexuales demuestra que el sexo no funda o no causa el género; al parecer, en este punto tiene razón, ya que en el caso del trans masculino no se cumple la idea normativa de que un cuerpo hembril ha de definir un género femenino o viceversa. Pero también, lo contrario parece ser cierto, puesto que no necesariamente la identidad de género puede determinar el cuerpo, aun con el apoyo de la tecnología, existen restricciones físicas y biológicas que imposibilitan la plena construcción de un cuerpo femenino o masculino. El mismo Coll-Planas analiza esta última situación, ya que lograr el equilibro entre en el género y el cuerpo que se desea es algo imposible (Coll-Planas, 2010, 213). Según él, es improbable eliminar por completo los rasgos del cuerpo machil o hembril, es muy difícil hacer que el género coincida con el cuerpo correcto, es decir, que coincidan sexo y género. Además, existen muchos riesgos y efectos secundarios, procesos muy largos, dolor postoperatorio, y no hay completa sensibilidad sexual en los genitales creados artificialmente (Coll-Planas, 2010, 218).

Tanto Coll-Planas como Halberstam recogen testimonios de personas trans con cuerpos postoperatorios como el caso de lsabelle, que se quejan de que no se sienten satisfechos con los resultados, que sus cuerpos postoperados son versiones defectuosas del verdadero cuerpo que desean; para ella, son cuerpos que han fracasado (Halberstam, 2008, 171).

Así, la voluntad no puede imponerse por completo a la materia. Aquí, se considera que no todo en el género y el sexo es una construcción social ni un determinismo biológico. El determinismo social o cultural es imposible, lo mismo que el determinismo biológico, vistos en términos absolutos. Ahora no cabe duda que hay casos en que lo biológico tiene una preponderancia y en otros lo social, cómo elaborar este modelo de la doble bidireccionalidad es algo complicado. A pesar de las críticas de Coll-Planas a las teorías biológicas o neurológicas del origen de la homosexualidad, es muy difícil negar la influencia de la biología, como en el caso de las personas XXY, entre otras.

Es interesante a este respecto, el análisis que hace Halberstam del género como performance, en relación con que la voluntad tampoco puede lograr una completa manifestación del género. Butler (2004) define el performance de género en tanto que la sexualidad y el género tienen una forma directa o indirecta, una realidad psíquica que les precede. Esta performatividad es lo que define el género y el cuerpo. Sin embargo, dice Halberstam que en el caso de la stone butch tal idea no se aplica, porque el género "se hace visible en ella en un performance que no es solo una repetición, sino que además es necesariamente imperfecta, defectuosa y tosca. Este performance imperfecto revela, además, que el género es siempre una lucha entre cuerpos y subjetividades, y cuando estos desajustes aparecen solemos hablar de patologías" (Halberstam, 2008, 151). La stone butch encarna aquella realidad en que el sexo, el género, la biología y la presentación de género no encajan. Es clara la idea de que la frontera se sitúa en la lucha entre el cuerpo y la subjetividad. 
Se interpreta aquí que en estos casos el género no hace al sexo, aunque lo intenta, y el sexo no hace al género, aunque influye en aquél.

Ahora, si bien muchas personas prefieren quedarse en el limbo de las fronteras, las razones pueden ser muy variadas: problemas de salud, temor a someterse a la operación, entre otras. En todo caso, habría que determinar cuánta libertad hay para mantenerse en el limbo y cuánto de condiciones materiales que limitan los puntos de llegadas a casas seguras de la identidad sexual y de género. Habría que considerar los mecanismos del cerebro que contribuyen a que nos adaptemos al medio contextual en el que nos desarrollemos, tampoco se pueden negar los mecanismos psicológicos que permiten las adecuaciones a las condiciones materiales en las que nos desenvolvemos.

Ahora, como bien lo expresan Coll-Planas y Halberstam, y como se refleja en Falso orgasmo, si un individuo se encuentra en el limbo de las fronteras puede asumir la gestión de su estado de incertidumbre e indefinición, puede optar por politizar su condición y vivir en un constante performance, y es claro que también puede justificar esa actitud indicando que es su libertad y que eso es lo que se quiere.

\section{Butch, transgénero y transexuales}

Según Halberstam, la butch transgénero representa la transición que la identidad requiere para el paso de la identidad de mujer al cuerpo masculino (Halberstam, 2008, 169), en este sentido es "una forma de transitividad de género que puede ser crucial para los sentimientos de muchas butches en lo referente a su corporeidad, a su subjetividad sexual e incluso a la legitimidad de su género" (Halberstam, 2008, 167). Mientras el transexual de mujer a hombre (FTM) implica un desplazamiento en las identidades y en la base corporal del contexto de la transexualidad, se trata de ajustes producidos en la mayoría de las identificaciones cruzadas de género, con la ayuda de la tecnología. Estos ajustes no implican un grado de inestabilidad y de transitividad (Halberstam, 2008, 169-170). Así, tal parece que para Halberstam el viaje llega a su fin. A estos grupos, pero en especial a los transgénero, son a los que ella llama género queer, el cual, no privilegia ninguna de las partes de la división.

Por su parte, Coll-Planas indica que la transexualidad se entiende, por lo común, como una etapa, un estado o proceso que acaba con la operación de reasignación de sexo (Coll Planas, 2010, 173). Al parecer, este es el punto de vista de Halberstam. Sin embargo, Coll-Planas considera que la transexualidad es un estado que estará presente a lo largo de la vida, no es un proceso que acaba, sino que es un continuo (Coll Planas, 2010, 174). A este respecto, a diferencia de la metáfora de la transitividad de Halberstam, Coll-Planas define al transgénero como lo que nunca se acaba, y lo denomina el náufrago del género. Esto tiene que ver con la idea de que nunca se llegará a una completa armonía entre el sexo y la identidad, aunque ambos autores queer arguyen que 
las identidades y las subjetividades son fluidas y flexibles; no obstante, esta idea se puede poner en cuestión, puesto que esta fluidez y flexibilidad, como se ha anotado, es restringida.

Siguiendo con la argumentación, hay una idea que comparto con CollPlanas: no se escoge ser homosexual, transgénero o transexual, tampoco se decide a voluntad sobre los sentimientos, tal parece que se reconoce implícitamente que hay aspectos que determinan dichas condiciones sexuales y de género (estas pueden ser biológicas, neuronales, psíquicas o sociales). Esto implica la idea de un esencialismo mínimo, algo que no podemos controlar a voluntad, sino que es algo que está ahí, como dado. Según él, lo que sí se puede decidir es cómo se asume la homosexualidad, la transexualidad y el transgénero, ya que los sujetos pueden decidir negarlos, aceptarlos y politizarlos. Así, las personas tienen un margen de acción y agencia en la conducción de su sexualidad y su género, es decir, los pueden gestionar.

Me parece que en esta misma línea de pensamiento se puede ubicar a Halberstam (2008, 176), cuando afirma que muchas identidades implican cierto grado de movimiento $(2008,171)$-nótese que no habla de un movimiento total, como cuando se dice que las identidades son fluidas- entre cuerpos, transgresiones y acomodaciones; así, según él, no necesariamente se pasa de una práctica sexual a otra por voluntad, sino que se dan procesos de adecuación y ajuste (Halberstam, 2008, 171). Pero, y a pesar de que algunas personas atestiguan que se mueven en esta fluidez, no parece que todas circulen por tales transcursos.

De manera que, decir que se pueden hacer los cambios de género o sexo por pura elección es algo complicado, porque, en el caso de los gais, lesbianas, transexuales y transgénero contradice las experiencias intuitivas de estas personas. Claro que se puede alegar que todos ellos están alienados y que asumen el discurso hegemónico del determinismo biológico que esencializa la condición homosexual, transexual y transgénero.

Según lo que indica Coll-Planas, es que si se argumenta que las orientaciones sexuales son estables, para la justificación de esa idea, se recurre a argumentos biologicistas, los que se interpretan de manera más o menos determinista. Pero hay casos, como ya se analizó, como el personaje intersexual del filme $X X Y$, en los que no parece que se pueda eludir la condicionante biológica, aunque, el personaje puede decidir si quiere continuar con su transición a hombre o mantenerse en su condición intersexual. Este es un caso límite en el que, al parecer, la determinante biológica no permite una completa elección, pero en donde la libertad tiene un margen de acción para la toma de decisiones.

A este respecto, si bien el recurrir a argumentos biológicos ha conducido a la dominación y el control de los cuerpos y el género, no necesariamente el argumento biológico tiene por que ser opresivo; puede servir para la liberación. Tampoco, el afán de afianzar el voluntarismo de la agencia, por parte de ciertos 
enfoques del constructivismo social, puede pretender negar lo biológico, de tal manera que se pueda afirmar que lo biológico no existe. A pesar de que CollPlanas argumenta que no se puede negar lo biológico, a veces parece hacerlo. Por ejemplo, él indica que no hay tal determinante porque no se puede decir que existan grupos determinados que se consigan identificar con un porcentaje estipulado de la población, y que tal pretensión es esencialista, porque asigna características a un grupo; a esto es lo que llama una posición minimizadora. En cambio, el autor sostiene que no existe una proporción de la población que sea homosexual, transexual y transgénero, sino que todas las personas tienen la opción de serlo, a esto es lo que llama un enfoque univerzalizador.

Pero, entonces, si todos pueden optar, quiere decir que se puede cambiar a voluntad de género y sexo; si es así, en dónde quedan las limitantes biológicas y contextuales. Del mismo modo, aparece el caso, como argumenta Butler en Falso orgasmo, en donde la identidad es práctica, es un hacer y está en la vida cotidiana; es así, que habría que preguntarse de quién o de quiénes, y si podemos optar por un género, mantenerlo de cierto modo o incluso alterarlo, dado que no son categorías fijas. No obstante, indica que también hay personas que experimentan su género como una cosa fija, esto es cierto, pero incluso un género fijo, se tiene que estar fijando día a día, aunque esta idea resulta incomprensible, ya que según Butler, existe tal género fijo, pero que a la vez no es tal, ya que constantemente hay que defenderlo de todo, puesto que existe el peligro de que pueda borrarse, porque nunca está fijado definitivamente, sino que de manera constante se rehace y se reestablece del modo que sea. Pero esto parece un voluntarismo de la agencia, una forma de idealismo. Además, esta perspectiva parece referirse más al comportamiento, la agencia y lo que hacemos, más que a lo que somos.

\section{Teoría queer y teatralidad}

En tiempos recientes el término queer se usa de manera muy lasa, en donde muchos hechos y fenómenos sociales de la diversidad sexual y las prácticas sexuales son incluidas; por ejemplo, se circunscribe a transgéneros, transexuales, gais, lesbianas, trabajadoras sexuales, leather, entre otras minorías y prácticas sexuales marginales. Por esto, ahora resulta difícil definir en qué consiste la teoría queer, ya que este es un término que se ha puesto de moda y que comienza a perder su valor analítico.

Según Tamsin Spargo, dicho concepto puede ser usado como sustantivo, adjetivo o verbo (esto último no queda claro cómo puede ser viable). Pero, en general, se le define en contraposición a lo normal o normalizador; esto refleja la misma vacuidad del término. Según Spargo, "no es un marco conceptual o metodológico singular o sistemático, sino colección de articulaciones intelectuales con las relaciones entre el sexo, el género y el deseo sexual” (Spargo, 2007, 15). 
dinámicas internas de crítica al movimiento gai y lésbico (López, 2008, 12). Esto coincide con lo propuesto por Spargo. Pero, tal crítica no implica un rechazo de la normatividad de las categorías gais y lesbianas, sino una comprensión diferente de la identidad y el poder (López, 2008, 54).

Lo común en las diferentes propuestas queer, según Spargo, es su oposición a la clasificación naturalizada y binaria del género. Los discursos son diversos, pero algunas propuestas son excesivamente utópicas (Spargo, 2007, 73). Un recurso metodológico de análisis utilizado en la teoría queer es la performativa, presente en Foucault y Butler. Según Spargo, la performatividad ha sido mal interpretada cuando se indica que podemos elegir a voluntad la pertenencia a un género. Dicho lo anterior, cabe decir que otro elemento común es que esta teoría trabaja en el ámbito de las subjetividades, y por lo general, tiene un predominio de un enfoque culturalista.

Spargo considera también que la teoría queer establece una conexión entre política y teatralidad $(2007,77)$. Sin embargo, en el análisis del documental Falso orgasmo se muestra cómo esta propuesta tiene sus límites políticos, ya que, realmente no permite la movilización política para el cambio social. En este sentido, definirse como queer es ser o estar en un constante performan$c e$, es decir, se ha de estar en una permanente acción teatralizante; esto es lo que le sucede al protagonista de Falso orgasmo, quien cada vez necesita un mayor grado de espectacularidad para poder transmitir sus ideas y convicciones, pero el impacto político es casi nulo.

Para López Penedo, el cuerpo es para la teoría queer el principal catalizador de los procesos de identificación que conforman la subjetividad queer, y este es el espacio en el que se articula el deseo de dicha teoría. La juntura del deseo se hace en primera persona y se concreta en la práctica de sexualidades no normativas (López, 2008, 14). En este sentido, también cabe preguntarse por el impacto político que lleva a la transformación social. Otro aspecto, es que se trata de una crítica cultural y un análisis de discursos, que intentan una reinterpretación cultural y la construcción de subjetividades. Pero es claro que no se fija en los procesos sociológicos. De esta manera, pueden establecerse las paradojas y las limitaciones de ciertos enfoques queer y de las perspectivas de la construcción social.

Por último, los filmes elaboran subjetividades de ficción que pueden indicar situaciones posibles de la vida real, muestran posibilidades de cómo los personajes gestionan sus identidades, no se cuestiona la condición sexual de las personas transgéneros y transexuales. Los filmes brindan referencias positivas o negativas a estas personas, aunque muchos de estos filmes no parecen cuestionar ciertas formas tradicionales de la masculinidad que asumen los hombres trans. Los filmes son maneras de visualizar la voz de las minorías trans. 


\section{Referencias}

Aaron, Michele. (2004). New Queer Cinema. A Critical Reader. Edinburgo: Edinburgh University Preess.

Armaiz, Anna. (2010). La condición sexual humana y la construcción de la realidad. Madrid: Biblioteca Nueva.

Belasko, Joseave (director) y Berri, Claude (productor). (1995). Garzon Maudit. Francia.

Brizendine, Louann. (2006/2010). El cerebro femenino. Barcelona: RBA.

Butler, Judith. (2004). Deshacer el género. Barcelona: Paidós.

Castañeda, Marina. (2006). La nueva homosexualidad. México: Paidós.

Castañeda, Marina. (1999). La experiencia homosexual. Para comprender la homosexualidad desde dentro y desde fuera. Barcelona: Paidós.

Chaves, Norberto. (2009). La homosexualidad imaginada. Vigencia y ocaso de un tabú. Madrid: Maia.

Clarke, Cheryl. (1981). Lesbianismo: un acto de resistencia. En Mérida Jiménez, Rafael. (Ed.). (2009). Manifiestos gays, lesbianos y queer. Testimonios de una lucha (1969-1994). Barcelona: Icaria.

Coll-Planas, Gerard. (2010). La voluntad y el deseo. La construcción social del género y la sexualidad: el caso de las lesbianas, gays y trans. Madrid: Egales.

Cristóbal, Tamiro. (2010). La homosexualidad en el cine. España: Ediciones Irreverentes.

Fernández-Alemany, Manuel y Sciolla, Andrés. (1999). Mariquitas y marimachos. Guía completa de la homosexualidad. Madrid: Nuer.

Halberstam, Judith. (2008). Masculinidad femenina. Madrid: Egals [1998. Female Masculinity. United States of America: Duke University Press].

Haslanger, Sally. (2000). El feminismo en la metafísica: gestionando lo natural. En Fricker, Miranda y Hornsby, Jennifer. (Eds.). Feminismo y filosofía. Un compendio. Barcelona: Idea Books.

Henderson, Mark. (2008). 50 Cosas que hay saber sobre genética. Madrid: Ariel.

Lacadena, Juan-Ramón. (2004). Biología del comportamiento sexual humano: genética y homosexualidad. Bilbao: Desclée de Brouwer.

142 Lerma, Diego (director). (2002). Tan de repente. Argentina-Holanda. 
López Penedo, Susana. (2008). El Laberinto Queer. La identidad en tiempos de neoliberalismo. Madrid: Egales.

Mangenti, María (directora) y Hall, Dolly (productor). (1995). The Incredibly True Adventure of Two Girls in Love. Estados Unidos.

Mérida Jiménez, Rafael. (Ed.). (2009). Manifiestos gays, lesbianos y queer. Testimonios de una lucha (1969-1994). Barcelona: Icaria.

Mark Mondimore, Francis. (1996). Una historia natural de la homosexualidad. Barcelona: Paidós.

McDowell, John. (1994). Mind and World. Estados Unidos: Harvard University Press.

Miles, Steve (director). (2010). Falso orgasmo. Estados Unidos.

Monsiváis, Carlos. (2010). Que se abra esa puerta. Crónicas y ensayos sobre la diversidad sexual. Médico, D. F.: Paidós.

Peirce, Kimberly (directora). (1993). Boys Don't Cry. Estados Unidos.

Pérez Álvarez, Marin. (2011). El mito del cerebro creador. Cuerpo, conducta y cultura. Madrid: Alianza.

Preciado, Beatriz. (2002). Manifiesto contra-sexual. Madrid: Opera Prima.

Pullappally, Ligy (directora) y Thomas, Jerry (productor). (2004). Sancharram (El viaje). India.

Ridley, Matt. (1999). Genoma. La autobiografía de una especie en 23 capítulos. México, D. F.: Taurus.

Rubin, Gayle. (1984). Notas para una teoría racial de la sexualidad. Biblioteca Virtual de Ciencias Sociales. Recuperado de http://webs.uvigo.es/xenero/ profesorado/beatriz_suarez/rubin.pdf

Sabsay, Leticia. (2011). Fronteras sexuales. Espacio urbano, cueros y cultura. Buenos Aires: Paidós.

Spargo, (2007). Foucault y la teoría queer. 2ª Ed. Barcelona: Gedisa.

Sykes, Bryan. (2003). La maldición de Adán. Barcelona: Debate.

Vélez-Pelligrini, Laurentino. (2008). Minorías sexuales y sociología de la diferencia, Gays, lesbianas y transexuales ante el debate identitario. España: Montesinos. 